\title{
Accurate Evaluation of Tumour Necrosis in the Preoperative Period: A New Challenge: In Reply
}

\section{Meng-Hsing Ho, MD and Chung-Bao Hsieh, PhD}

Division of General Surgery, Department of Surgery, Tri-Service General Hospital, National Defense Medical Center, Taipei, Taiwan

\section{TO THE EDITORS}

In their letter, we appreciate that Marzano et al. mention the limitation of radiological modalities, such as utilizing magnetic resonance imaging (MRI) or computed tomography $(\mathrm{CT})$. In fact, it is difficult to precisely calculate the tumor necrosis percentage by radiological material and compatibility with pathological results, and it may otherwise be a reliable biological criterion of liver transplant for prognosis. In our experience, MRI is better than $\mathrm{CT}$ in evaluating the bioactivity of hepatocellular carcinoma after locoregional therapy; however, CT scan and automatic three-dimensional reconstruction applied by the authors may be an advanced technique, and may improve the effectiveness of the radiological evaluation.

(C) Society of Surgical Oncology 2017

First Received: 20 October 2017;

Published Online: 2 November 2017

C.-B. Hsieh, $\mathrm{PhD}$

e-mail: albert0920@yahoo.com.tw 